\title{
REGRAMENTO(S) E REGULARIDADES LINGUÍSTICAS EM DISCURSOS NA/SOBRE A FORMAÇÃO DE PROFESSORES NO CONTEXTO BRASILEIRO: IMPLICAÇÕES E(M) CONFLITOS
}

\author{
Nadia Dolores Fernandes Biavati*
}

\begin{abstract}
RESUMO: O objetivo do artigo é apresentar conflitos que perpassam a formação do professor, afetando-lhe o modo como percebe sua identidade profissional. Em estudos como o de 2009, mostrei como o professor de Língua Portuguesa é atravessado por ideologias que interpelam o olhar para a profissão e, nessa visão, vale questionar em que medida os regramentos devem ser valorizados ou se o professor deve trabalhar com uma conduta pautada no conjunto de fatos linguísticos e a interação dos sujeitos. No presente texto, lido com a complexidade desse questionamento, pois acredito que o professor ora sofre efeitos de um pré-construído por interpelações ideológicas, ora não, intervindo nas suas escolhas a partir de uma rede de concepções e valores que lhe são trazidos representados e (re)construídos continuamente. Destaca-se o poder que, de maneira fluida, ajuda a entronizar práticas tornando potentes as estratégias de dominação efetivas na validação cega à regra.
\end{abstract}

PALAVRAS-CHAVE: Regramento; Contexto brasileiro; Formação de professores; Ensino de língua materna.

\section{Introdução}

No presente texto, apresento algumas implicações que se dão entre o fazer e o pensar sobre o dar aulas de língua materna nos cursos de formação profissional. A ideia que se de-

\footnotetext{
* Doutora em Estudos Linguísticos pela Universidade Federal de Minas Gerais (UFMG). Professora adjunta da Universidade Federal de São João Del-Rei (UFSJ).
} 
fende no contato com o dar aulas de Português é que, muitas vezes, o professor se vê atravessado por ideologias que interpelam o ensino e trazem dúvidas, invocando questionamentos sobre em que medida é importante trabalhar o olhar para a língua como um modo instrumental de trazer regras. Por outro lado, é importante que se reflita sobre as implicações das regularidades abafadas em nome desse olhar à regra.

Interessa, portanto, destacar fato e regra linguísticos como aspectos fundadores para o ensino e inseridos na sociedade sujeitos a um conjunto de restrições, aspectos que repercutem na formação do professor de Português no contexto brasileiro, colonizado. Acredito que, em um dado momento da história, ambos foram um só - usos como norma linguística e padrão social de comportamento linguístico - e sistematicamente inseridos no trabalho com o idioma e com a formação de professores. Aos poucos, se constituíram como noções que foram se afastando uma da outra, na medida em que a institucionalização de usos linguísticos se deu pela força dos regramentos trazidos pelos princípios regidos pelo colonizador, somado à implantação de mecanismos de gramatização como compêndios e gramáticas, documentos cujos olhares ao idioma vislumbram determinados usos cobrados como aceitos socialmente.

Ficou mais visível pela via da regra, portanto, o domínio de poderes que acabou por trazer cobranças aos sujeitos em suas interações. Trazendo luz a essas estratégias, refletese, a seguir, sobre a força do hábito que se transformou em regras de usos linguísticos trabalhados socialmente e seus efeitos na formação de professores. No cumprimento do propósito da presente reflexão, abordo primeiramente a transformação do hábito em regra, bem como a força que adquirem esses regramentos nos dizeres em determinadas práticas sociais. Em um segundo momento, relaciono fato e regra ao letramento acadêmico do professor, pensando no modo como a formação deve equilibrar ambos como processos de reflexão para se produzir eventos didatizáveis. 


\section{Quando o hábito tornou-se regra: reflexões para o ensino}

O uso da linguagem nas relações sociais se dá em dois caminhos: (1) ora marcado pela naturalidade em um processo de interação, pelo uso, o chamado fato linguístico; (2) ora marcado pela regra como condição indispensável para que se reflita sobre as ações no âmbito escolar. Essas duas concepções são importantes para a compreensão de conflitos com os quais professores têm de lidar no cotidiano escolar, mesmo após anos de formação, pois estamos em uma sociedade em mudança, que requer movimentos de dizeres em gêneros que só se instauram na prática social.

A esse respeito, Marcuschi (2008) reflete sobre o modo decisivo como os gêneros discursivos, quer sejam formais, quer sejam mais ou menos formais, quer sejam informais (no contínuo das retextualizações), somente se manifestam na prática social. A problemática se dá, pois, em que medida valores que destacam tanto o trabalho do professor com a descrição das regularidades do sistema linguístico (o fato linguístico), quanto concepções que (re)apresentam as formas de uso socialmente dominantes (a regra) norteiam a prática de dar aulas. Acredito que essas concepções, ora se revezam, ora se privilegiam, ora se destacam, concomitantemente e simultaneamente, dependendo da política linguística praticada para o profissional, pelo sujeito que ensina e pelas instituições de ensino no País. No caso do ensino de dar aulas de Português, as práticas de ensino-aprendizagem se dão norteadas, muitas vezes, por práticas fundamentadas a partir de exercícios incentivados tanto com o viés de gramáticas normativas quanto com as regularidades dos dizeres, que se dão como instrumentos que pontuam esses dois aspectos, privilegiando a norma social para o ensino de Português.

\section{Conflitos e dilemas na formação}

O trabalho com os gêneros como objeto de ensino é consenso nas orientações curriculares para o ensino de Língua Portuguesa no Brasil (BRASIL, 2002). A pesquisa e a reflexão sobre documentos de orientação para o ensino como PCN e Diretrizes Curriculares Nacionais é dado de reflexão para os professores em formação. Em disciplinas que 
discutem a prática de ensino de Língua Portuguesa, uma questão que atravessa o ensino de língua materna é que a força dos fundamentos de ensinar/aprender Língua Portuguesa como disciplina institucionalizada que se orienta pelo trinômio fato, regra, gramática.

Nessa direção, a discussão que orienta professores passa por pontos de reflexão e de questionamentos se dá com:

- $\quad$ O estudo da língua e das linguagens deve nortear as regularidades na constituição de um idioma, aspectos que se dão seguindo tendências do uso;

- O estudo de elementos e formas de uso caracterizando regras segue o princípio da adequação do uso linguístico a aspectos socioculturais, bem como o modo como sujeitos interagem ou devem interagir, considerando as relações de poder que circulam socialmente;

- O estudo de gramáticas tende a se apoiar no viés normativo em detrimento do seu caráter descritivo, seguindo com o normativo o modo como os sujeitos, em seu papel social e o que se quer atingir, determinados usos da norma padrão e rejeitando outros.

E a tendência, independentemente da época, é que tanto professores quanto professores em formação percebam, por vezes, os três como sinônimos (ainda que não o sejam) e como base para reflexão para a sala de aula. Acreditamos, portanto, que há um trabalho de naturalização institucional sobre a/da gramática normativa como regra em detrimento da ideia de usos pela força da adequação de usos, repercutindo a força e os sentidos desse trinômio para as práticas no ensino.

Nesse sentido, é histórico da profissão do professor de Português seguir as regras que lhe são impostas pelas políticas de ensino, pelas orientações estatais e pela força dos dizeres tomados como regra social. Explica-se, assim, que algumas instituições de ensino em que materiais ou instrumentos didáticos negligenciam por vezes a finalidade dos estudos da língua como fato, aspecto que faz com que se assimilem as regras como base para o ensino, e o fato linguístico como regra. Ou ainda, o fato é relegado a um conhecimento a mais que não chega à população leiga, que passa ou passou por processo de escolarização. 
Em tese de doutoramento (BIAVATI, 2009), discuti três concepções (regra, gramática e norma) que se confundem pelo próprio rumo dado a elas na História. A esse respeito, vale observar que, conforme pontuam estudiosos da Filosofia (LIMA VAZ, 2000) e do Direito (KELSEN, 1998), a construção da norma liga-se à própria construção do cidadão da forma como o entendemos na contemporaneidade. Entende-se o fato como ligado à norma linguística (BAGNO, 2001). Nessa direção, a sociedade se constitui a partir da convivência entre os homens. O modo de viver do homem na sociedade é o que se chama de ethos.

Segundo Lima Vaz (2000, p. 12), o termo ethos originalmente é entendido de duas formas: com eta inicial e com épsilon inicial. A primeira diz respeito à morada do homem, no sentido do lugar em que ele atua. Nesse sentido, o ethos corresponde ao costume, que é o mundo habitável pelo homem. O domínio da natureza (da determinação) é quebrado e abre o espaço humano de convivência, assim, o espaço do ethos é construído e constantemente reconstruído. A segunda acepção designa o ethos como o comportamento humano construído pela constância do hábito, hábito de agir não sempre, mas quase sempre, não em virtude de uma necessidade natural. Daí a distinção entre natural e habitual. $\mathrm{O}$ termo dessa disposição é hexis, que é o princípio de ação que exprime sua autarquia, com a inserção do homem agindo e designando regularidades. Assim, o ethos designa o processo genético do hábito ou disposição habitual para agir de uma determinada maneira. É justamente entre o processo de formação do hábito e seu término como disposição permanente do agir de acordo com as exigências do bem que o ethos se desdobra como espaço de realização do homem, como lugar de sua práxis. Quando se fala em ciência, da natureza ou do ethos, não se pode indicar o estudo de uma comunidade.

Quando se diz ciência, pressupõem-se princípios racionais que podem ser aplicados. Ciência pressupõe universalidade. E formação profissional pressupõe que o profissional em formação se coloque em contato com o que se convenciona com o saber logicamente estabilizado. No entanto, o modo como se tomam as regras da escola nos faz esquecer 
muitas vezes que os limites por vezes tênues entre regramentos e hábitos, naturalizando e tornando a regra como uma forma comum de se compreender a realidade.

Na relação entre saber estabilizado e exercício do poder surgem convenções apoiadas na ciência, apoiadas como tal no discurso. Seguindo as ideias de Foucault, em estudos sobre a microfísica do poder, é pela ciência que o hábito evolui para o costume e, após, para a regra. O olhar naturalizado a um determinado dizer ou a um determinado modo de dizer (e no ensinar) se constitui(em) discurso(s). Para Foucault (1996, p. 17), em toda a sociedade, a produção do discurso é ao mesmo tempo "[...] controlada, selecionada, organizada e redistribuída por certo número de procedimentos", isto é, práticas e formas de ver que nos são trazidos como formas de instrumentação, como iniciativas de poder para o poder. O costume, tanto como um modo de dizer, quanto como um conjunto de dizeres, em um dado momento, passa a ser regra. Se o professor, ao dar aulas de Língua Portuguesa, aciona somente os gêneros cabíveis nos regramentos sociais, considera-se somente uma parcela do agir humano em condições de interação.

Contudo, entende-se que, quando se propôs uma ciência do ethos, estava pressuposta uma norma de ação válida para todos, prescrições universais. No convívio humano, não agimos da mesma forma, mas buscamos a unidade na multiplicidade. A busca se concentra em achar um ponto fixo (regularidade) nas nossas ações, como se acha na natureza, ainda que o homem não se caracterize pela fixidez nas ações. $\mathrm{Na}$ busca da estabilidade, o espaço humanizado se torna normatizado/regulado a partir do momento em que o ethos é rompido e se circunscreve no domínio das necessidades da natureza.

Um conjunto de costumes disseminados na sociedade tornou-se comportamento natural, gerando o hábito, que passou a ser regulado para melhor desempenho nas relações sociais, o que implica a interpelação de ideologias cercadas pelo poder na definição desses costumes. Portanto, o agir passou de regularidade a regulação a partir da decisão de alguns sobre o que poderia colaborar com o melhor desempenho social. Instituíram-se as regras sociais, e, por consequência, as regras linguísticas ligadas ao elo social entre os sujeitos. A decisão do uso das regras passa, portanto, por um trabalho de decisão do que é válido e do 
mascaramento pela razão e pela chamada verdade: para Foucault (1996), através das instituições, decide-se o que pode e o que deve ser dito (não ao acaso), já que quem decide é investido pelo poder. O processo de exclusão do dizer e das regras não passa pelo conflito ou pelo afrontamento direto. Para Foucault (1996), as verdades são decididas a partir de "um discurso verdadeiro", de uma ordem (da lei) que se constitui como o saber que é valorizado, a partir de práticas discursivas da ciência, da razão, do uso logicamente estabilizado, sujeito a poucos questionamentos.

\section{Saberes didatizáveis com o professor eleito como o porta-voz para lidar com o "uso sem regras"}

Com a força da instituição, no contexto brasileiro, o professor mais respeitado ainda é o porta-voz da solução para o "problema dos dizeres sem regras", e a escolarização ganha contornos de solução para as variações na língua de um país continental que o aluno leva para a sala de aula. Refletir sobre a didatização de saberes é um caminho para pensarmos a amplitude das escolhas para o ensino que, no ensino de língua materna, reflete a importância que a sociedade dá aos usos regrados e como e a quem eles significam. Para Aléong (2001, p. 154), “[...] a importância que o ensino da gramática tem em nossa experiência escolar nos faz esquecer frequentemente que a grande maioria das línguas do mundo foram e são ainda fenômenos sobretudo orais", já que o referencial de ensino é sempre, em qualquer situação sociocomunicativa, o padrão escrito. Também há tendência de que o binômio variação/norma seja sempre visto de forma unilateral: ignora-se a variação na ilusão da língua única e pontua-se à língua um conjunto de regras que bonificam aqueles que dominam o padrão, o privilégio de pertencer ao grupo não estigmatizado, com o uso perpetuado pelas relações de poder. A esse respeito, Haugen (2001, p. 101) afirma que "[...] como norma social, um dialeto é uma língua excluída da sociedade polida”.

Reafirma-se, portanto, a condição de que, ao produzir dizeres, os sujeitos criam, mas sofrem efeito do simbólico, submetem-se à língua e à história (ORLANDI, 2001). Ao observar os discursos, percebe-se a atualização da memória e, no processo de formulação, 
o que se chama de trajetos de memória que evidenciam a fragmentação e a heterogeneidade, há um "eu” no "nós” e um "nós” no “eu”: as vozes assumem posições dos sujeitos enunciadores/professores que por vezes não significam posições dos indivíduos. É a materialização de um dizer que às vezes se mostra ilógica e mutável, a partir dos vários condicionantes e das situações. Para Orlandi (2001, p. 45), "o sujeito se constitui por uma interpelação", e como tal admite ideologias, se inscreve na história e, na atualização, constitui e é constituído a partir de relações, crenças e valores na prática social. Como materialização do dizer, o texto é unidade e dispersão e, na textualização da memória, há movimentos diversos, "gestos" de didatização, construindo sentidos. Isso implica que os sujeitos são livres, contudo são presos à construção dos sentidos, são ligados ao pré-construído (em constante ligação com o interdiscurso e a memória discursiva), sempre "redizendo" e "reconstruindo" as possibilidades no intradiscurso. É o agenciamento da unidade pela dispersão.

Se os sentidos são ressignificados no discurso, é porque os sujeitos se inscrevem na história. A forma linguística torna-se sentido, signo, na medida em que "[...] a historicidade é constitutiva da espessura semântica da linguagem" (DIAS, 1996, p. 25). Ou seja, a formulação é a realização de um possível, pois há um processo sócio-histórico que se reflete na linguagem, ao mesmo tempo que a linguagem ressignifica o processo sócio-histórico. A palavra em movimento (ORLANDI, 2001), que é o discurso, significa o dizer na instância de circulação histórica, emprestando "corpo" às interpretações. A formulação dos dizeres sobre ensinar, portanto, carrega marcas da historicidade, e o texto seria o produto do possível, trazendo também as marcas do sujeito interpelado pela história colonizada, pelos efeitos de sentido provocados pelas ideologias do bem-dizer, projetadas no pré-construído. Essas marcas remetem ao sujeito interpelado pelo capitalismo da técnica, pelas forças do dizer, pela memória, pelo "outro”, pelo profissional do ensino que trabalha, detendo o "poder sobre as letras" e ao mesmo tempo pelo sujeito oprimido, fragmentado, que é explorado pelo trabalho, que compreende as regularidades, mas se vê interpelado pelas regras. Há um contínuo que se ressignifica no processo sócio-histórico. Portanto, a formulação marca o discurso como constitutivo de uma memória, de sentido(s), da história. 
Em O discurso: estrutura ou acontecimento, sua última publicação em vida, Pêcheux (2002) apresenta caminhos para a discussão de uma análise de discurso: o primeiro é a visão do discurso como acontecimento (discurso: substantivo abstrato), indicando o reconhecimento da opacidade do signo; o segundo é a visão do discurso como estrutura (discurso: substantivo comum), o que implica conhecer procedimentos técnicos no tratamento dessas estruturas; e o terceiro diz respeito à descrição e à interpretação dos procedimentos apontados na segunda visão, apresentando resultado para as diversas formas de análise de objetos, o que não quer dizer, entretanto, que haja solução definitiva para questões que vêm à tona nesse processo. Os trajetos de sentido que ocupam os saberes e as significações dos professores indicam um saber que se reveza entre o saber oprimido pelas regras no sistema e, ao mesmo tempo, os discursos de autoridade, indicando representações do/para o professor.

\section{$4 \mathrm{O}$ dizer autorizado e a força da instituição - Letramento acadêmico}

Ao dizer de professores de Português muitas vezes é atribuído status de ciência, por se tratar de enunciação de alguém autorizado academicamente para discorrer sobre a língua, que é capacitado como tal (ou deveria ser) para lidar com a ciência (discurso de verdade ou defendido como tal) nos cursos de formação. Pêcheux (2002) questiona o papel atribuído à ciência, ao lidar com uma multiplicidade de técnicas de gestão social dos indivíduos, o que aparenta coerção lógica disjuntiva. Para o autor, ser ou não ser algo implica, por exemplo, o uso regulado de proposições lógicas, a recusa ou aceitação de certas marcas de distância discursiva. No espaço discursivo logicamente estabilizado constituído como saber acadêmico, com lugar social e pessoas autorizadas, como é o caso da instituição escolar, supõe-se o controle do dizer. Nesse sentido, é necessário que em qualquer tipo de análise se reconheça que, estruturalmente, todo enunciado se inscreve em espaços discursivos. Portanto, o dizer se filia ao como é instituído o/como algo deve ser dito. 
Para Foucault (2005, p. 17), o dizer autorizado pelo suporte institucional se mantém em uma prática discursiva ${ }^{1}$ que se apoia na vontade de verdade: há um conjunto de práticas, como a pedagógica, que se servem de um suporte institucional que responde ao desejo do poder. Nesse espaço, a dimensão do poder é diluída, não é simplesmente hierarquizada, mas difusa. O poder não se mostra, simplesmente por haver um conjunto de relações de classe que se manifestam nas instituições: pressupõe exercício nas relações sociais, nas práticas cotidianas, e nem sempre é perceptível, pois é naturalizado, pressupõe a troca entre os sujeitos. Nesse sentido, a formação pela instituição escolar é o canal de condução ao dizer autorizado, mas também um lugar de conflito entre os dizeres.

Para Cardoso (2003, p. 52),

[...] muito embora a escola seja um importante aparelho ideológico do Estado e como tal produza sujeitos sociais, a escola é também um lugar de conflitos e de luta ideológica, em que as consciências políticas podem ser constituídas, mas também alteradas num processo realmente revolucionário.

No contexto brasileiro, formar professores de língua portuguesa carrega dilemas: são sentidos que se projetam nas condições brasileiras os regramentos da língua (por vezes tomados artificialmente) para o mundo do trabalho, e isso implica (re)considerar a flexibilização. Pois, não são as técnicas dos dizeres ou o domínio cego ao regramento dos cursos preparatórios, como forma de regulação no dizer que ensina o professor a dar aulas. A ideia é saber lidar com uma política discursiva que perpassa o papel do professor de língua materna, cabendo a ele ensinar o aluno a operar um sistema linguístico e a produzir enunciados adequados às situações.

${ }^{1}$ A prática discursiva conceitua-se como a produção, a distribuição e o consumo de um texto. Segundo Fairclough (1992), ela é constitutiva de modo convencional e criativo. Em minha dissertação de mestrado (BIAVATI, 2001), observo que a prática discursiva contribui tanto para a reprodução da sociedade como tal (as identidades, as relações sociais e os sistemas de conhecimentos e crenças) quanto para a transformação da sociedade. 
Como reflexo dessa realidade, no contexto profissional de língua materna, ao mesmo tempo que se valoriza o ensino de práticas de linguagem que sejam significativas no mundo contemporâneo, o professor não apenas tem de ser o portador de "ferramentas linguísticas" que facilitem o como se expressar em determinada situação, mas também deve repassá-las ao aluno, como se a língua fosse um sistema definitivo, reproduzindo a ideia saussureana da langue. Isso significa nem sempre fazer o processo de transposição didática de maneira tranquila, pois se entende que "repassar" pressupõe alimentar um diálogo constante sobre o papel da técnica, da regra e a quê e a quem, por vezes, ela serve.

\section{0 pré-construído interfere na profissão: professor-mosaico sujeito ou assujeitado?}

Estudiosos, a exemplo de Rocha (2002), observam o grande volume e a variedade de atividades que hoje são atribuídas ao professor atualmente, o que acaba revelando um conjunto confuso de atividades exercidas por ele devido ao conjunto de tarefas que foram acumulando a essa profissão ao longo da história e do rumo que foi atribuído ao professor de língua portuguesa. Devido a esse gerenciamento da multiplicidade, é que Rocha (2002) designa-o como "mosaico". Cardoso (2003, p. 52) considera que os sujeitos-professores não são meros portadores da hegemonia discursiva. Pontuados pela prática da regulação (o seguir a regra) e pela regularidade (observação ao fato) da língua, os professores tomam a hegemonia e a reinventam a partir do seu olhar, de outros olhares. É nesse sentido que se justifica a sua posição e as suas práticas como "mosaico". Assim, o professor se inscreve na instituição filiando-se a saberes e, com isso, é alçado por vezes à condição do detentor e vigilante da língua pela formação no curso de Letras; portanto, no seu fazer profissional, ele toma para si o papel do representante da regra e toma a voz do "saber a língua para ensiná-la”.

Essa condição rememora as reflexões de Pêcheux (1997), em sua chamada segunda fase de trabalho quando admite o sujeito assujeitado ao discurso, visão diferente da ACD proposta por Fairclough, que entende o sujeito capaz de fazer suas próprias escolhas diante das redes de discursos que dominam as instituições. Relacionando a rede de dizeres do 
professor de Português/língua materna, percebe-se, em muito, a interpelação do indivíduo em sujeito de seu discurso orientada pela "[...] identificação do sujeito com a formação discursiva que o domina" (PÊCHEUX, 1997, p. 163). Nesse sentido, as condições já seriam praticamente levadas por uma rede de valores ao professor para a sua escolha de concepções, procedimentos e práticas. Desse modo, o pré-construído atua de forma significativa como um conjunto de elementos que se impõem como realidade da obrigação do "como dizer”, pois “[...] a identificação com um dizer, com uma prática apoia-se numa realidade imposta pela interpelação ideológica, através do pré-construído" (PÊCHEUX, 1997, p. 163). Isso significa que, pela ideologia, as formações discursivas se determinam e, a partir de uma exterioridade (interdiscurso), se compõem na interioridade (intradiscurso).

A partir dessas duas visões, é importante frisar os desdobramentos a que o professor de língua portuguesa se submete, uma vez que precisa ter consciência sobre esses processos e as implicações desses nos chamamentos trazidos pela sociedade à profissão, ao mesmo tempo em que cabe a ele fazer as escolhas sobre o que é adequado e como é adequado ensinar. Entretanto, o fato é que o "mosaico" permanece: ora ele sofre efeitos de um pré-construído em interpelações ideológicas, como memória, ora se organiza criticamente, apresentando, de modo autônomo, suas escolhas a partir de uma rede de concepções e valores que lhes são apresentados, difundidos e repetidos, seja na formação profissional, seja no cotidiano. Mas será que isso é temerário? Foucault (2005, p. 73), trabalhando com os efeitos da microfísica do poder, questiona: "Mas o que há assim de tão perigoso por as pessoas falarem, qual o perigo dos discursos se multiplicarem indefinidamente? Onde é que está o perigo?” Para o autor, a legitimação é uma forma de se estabelecer o controle do discurso, tornando essa uma importante forma de atuação dos regramentos, que levam os professores a enfatizar indefinidamente a força dos regramentos sociais, esquecendo, por vezes, o exercício da visão crítica para a realidade dos textos, voltando energias sempre para o "treino" à norma culta. 
Ora, esta vontade de verdade, tal como os outros sistemas de exclusão, apoia-se numa base institucional: ela é ao mesmo tempo reforçada e reconduzida por toda uma espessura de práticas como a pedagogia, claro, o sistema dos livros, da edição, das bibliotecas, as sociedades de sábios outrora, os laboratórios hoje. Mas é também reconduzida, e de um modo mais profundo sem dúvida, pela maneira como o saber é disposto numa sociedade, como é valorizado, distribuído, repartido e, de certa forma, atribuído (FOUCAULT, 2005, p. 72).

Foucault reafirma o controle do discurso, que o torna legítimo na medida em que há o respaldo das instituições, uma vez que as mesmas seguem os valores disseminados na ordem da lei. Assim, as instituições determinam, através do seu discurso, as concepções e as práticas de inclusão e de exclusão na sociedade, trazendo a força do pré-construído como um mecanismo de reforço dos discursos de consenso.

Percebe-se que o pré-construído sobre a instituição escolar, como esse conjunto de dizeres que se sustentam no fazer docente se relaciona com a ordem do discurso na medida em que o pré-construído se constitui a partir de um conjunto de práticas em relação temporal, no a priori do dizer, sustentando a memória discursiva. Já a ordem do discurso se constitui por seleção de elementos a partir do referencial de escolha pela interpelação ideológica. Dizeres que estão no consenso se estabilizam pela rede de poderes que se solidificam e solidificam os dizeres. Pode-se concluir, então, a força do fazer docente sobre ensinar a língua se constitui pelo já-dito, o a priori no discurso pela memória e pelo elaborado na relação do dizer, a partir da ordem do discurso, o conjunto de dizeres que circulam e fundamentam os afazeres e as crenças da instituição escolar sobre o que é letramento e como ele deve acontecer. Há um conjunto de processos que são constitutivos e constituídos na prática social, orientam o dizer e, por isso, a formulação se estabelece como a realização de um possível, mas um possível que se orienta muitas vezes pelo hegemônico, pela decorrência. 


\section{Considerações finais}

Tomamos a denominação de professor-mosaico, acreditando no poder dessa designação como o lugar dos deslocamentos de sentidos, já que a identidade profissional do professor, definitivamente, se constitui de forma fluida e multilateral, pelo intencional e pelo não intencional, pela memória construída sobre ensinar uma língua materna colonizada, com a força do pré-construído.

Paralelamente, as construções e as formulações sobre o saber metalinguístico do professor acerca da gramática, o fato, os regramentos por se tratarem do reflexo de uma política linguística que se dá nos entrelugares: esses saberes vêm se constituindo de forma múltipla, em compreensão dos usos linguísticos como fato e desses usos como regra, em revezamento, ou mesmo simultaneamente como produtos constitutivos do sistema de ensino.

O importante é que, nos cursos, o professor que forma e o profissional em formação sejam conscientizados sobre a força dos discursos que regem a instituição, a que e a quem essa rede de discursos sobre os regramentos traz imposições que discriminam e atingem a população, impondo o domínio dos saberes estabilizados como ciência que rejeita e segrega os sujeitos que se comportam de forma diferente ou que simplesmente trabalha mais com as regularidades, refletindo sobre a força e os efeitos de sentido dos usos. Urge que o professor em formação adquira na licenciatura a consciência para lidar com o fato linguístico e os regramentos sociais e a implicações dessas escolhas, portanto.

Reivindica-se aqui que se deve discutir com ênfase nas licenciaturas as implicações da força da técnica que prevalece em uma sociedade que se quer mostrar eficiente, cujo discurso parece ser eficiente somente quando favorece o "bem expressar", o que é, claro, ilusão. A esse respeito, nota-se que a noção corriqueira de ensino de língua divulgada na mídia é a de que a correção "de erros" é o fundamento para o aprendizado de língua materna. Programas midiáticos e seções de jornais sustentam o professor como a "gramática normativa ambulante", "o vigilante da língua”, que se constitui também pelo perfil enciclopédico, reforçado com práticas da correção com o "usa-se assim..., não assim”, “o correto 
é de uma forma, não de outra", pensamentos que reiteram o professor em um altar que em pouco ajuda realmente que o aluno se torne letrado, como sujeito capaz de agir, ler, escrever e refletir com adequação diante das práticas sociais em uma sociedade múltipla, com suas múltiplas semioses, com inúmeras possibilidades de leitura e escrita, seja real ou virtualmente. Logo, a noção de ensinar a língua se dá com inúmeros pontos, com discussão de verdades, a partir de, inclusive à reflexão ética sobre o controle das instituições, pois

[...] a maior das verdades já não estava naquilo que o discurso era ou naquilo que faria, mas sim naquilo que o discurso dizia: chegou porém o dia em que a verdade se deslocou do acto ritualizado de enunciação, eficaz e justo, para o próprio enunciado: para o seu sentido, a sua forma, o seu objecto, a sua relação à referência (FOUCAULT, 2005, p. 26).

Deve-se observar, assim, os perigos dos deslocamentos dos dizeres e seus efeitos, fugidios, mas eficazes. São esses que se devem trazer à tona, quando ensinamos aos alunos as tramas das letras.

\title{
LINGUISTICS REGULATION(S) AND REGULARITIES IN DISCOURSE IN/ABOUT THE TEACHER TRAINING IN THE BRAZILIAN CONTEXT: IMPLICATIONS IN/AND CONFLICT(S)
}

\begin{abstract}
The purpose of this article is to present some conflicts that permeate the teacher's training, affecting the way she/he perceives his/her professional identity. In studies such as the one I published in 2009, I showed how the Portuguese teacher is seen through ideologies directing a certain look to this profession and, from this point of view, it is worth to question to what extent the rules should be valued or if the teacher must work with a behavior guided by the set of linguistics facts and in the interaction of subjects. In this text I deal with the complexity of this question because I believe the teacher at times suffers the effect of a pre-built by ideological interpellations and at other times does not, participating in his/her choices from a set of concepts and values that are brought to him continuously represented and (re)constructed. There is a highlight on the power that flowingly helps to enthrone practices empowering the domination strategies effective in a validation blind to the rule.
\end{abstract}

\section{KEYWORDS:}

Regulation; Brazilian context; Teacher training; Mother tongue teaching. 


\section{REFERÊNCIAS}

ALÉONG, S. Normas linguísticas, normas sociais: uma perspectiva antropológica. In: BAGNO, M. (Org.). Norma linguística. São Paulo: Loyola, 2001. p. 145-174.

BIAVATI, N. D. F. Entre o fato e a regra: unidade e fragmentação na constituição da identidade e representação de valores e práticas do professor-mosaico. 2009. Tese (Doutorado em Estudos Linguísticos) - Faculdade de Letras, Universidade Federal de Minas Gerais, Belo Horizonte, 2009.

BIAVATI, N. D. F. O lugar do trabalhador e das relaçoes de trabalho em propagandas publicadas em revista brasileira de informação geral: um estudo de caso em ACD. Dissertação (Mestrado em Estudos Linguísticos) - Faculdade de Letras, Universidade Federal de Minas Gerais, Belo Horizonte, 2001.

BRASIL. Ministério da Educação. Secretaria de Educação Fundamental. Parâmetros curriculares nacionais: língua portuguesa 2. 2. ed. Rio de Janeiro: DP\&A, 2000.

CARDOSO, S. B. Discurso e ensino. Belo Horizonte: Autêntica, 2003.

DIAS, L. F. Os sentidos do idioma nacional: as bases enunciativas do nacionalismo linguístico no Brasil. Campinas: Pontes, 1996.

FOUCAULT, M. A ordem do discurso: aula inaugural no Collège de France, pronunciada em 2 dez. 1970. São Paulo: Loyola, 1996.

FOUCAULT, M. Microfísica do poder. 21. ed. Rio de Janeiro: Graal, 2005.

HAUGEN, E. Dialeto, língua, nação. In: BAGNO, M. (Org.). Norma linguística. São Paulo: Loyola, 2001. p. 97-114.

KELSEN, H. Teoria pura do direito. São Paulo: Martins Fontes, 1998. p. 4-25.

LIMA VAZ, H. C. Escritos de filosofia II: ética e cultura, São Paulo: Loyola, 2000.

MARCUSCHI, L. A. Produção textual, análise de gênero e compreensão. São Paulo: Parábola, 2008.

ORLANDI, E. Análise de discurso: princípios e procedimentos. 3. ed. Campinas: Pontes, 2001.

ORLANDI, E. Discurso e texto: formulação e circulação dos sentidos. 2. ed. Campinas: Pontes, 2005.

ORLANDI, E. Lingua e conhecimento linguístico: para uma história das ideias no Brasil. São Paulo: Cortez, 2002.

ORLANDI, E. O estado, a gramática, a autoria - língua e conhecimento linguístico. Revista Linguas e instrumentos linguísticos. História das Ideias Linguísticas. n. 4/5. São Paulo: Pontes, dez. 1999/jun. 2000. p. 19-34. 
ORLANDI, E. P.; GUIMARÃES, E. Institucionalização dos estudos da linguagem: a disciplinarização das ideias linguísticas. Campinas: Pontes, 2002.

PÊCHEUX, M. O discurso: estrutura ou acontecimento. 3. ed. Campinas: Pontes, 2002.

PÊECHEUX, M. Semântica e discurso. Campinas: Ed. Unicamp, 1997.

ROCHA, L. C. A. Gramática: nunca mais; o ensino da língua padrão sem o estudo da gramática. Belo Horizonte: Ed. UFMG, 2002.

Recebido em: 26/07/2018.

Aprovado em: 15/08/2018. 